\title{
ON THE POSTSEISMIC DEFORMATION AT IKUNO IMMEDIATELY AFTER THE 1984 YAMASAKI EARTHQUAKE
}

\author{
Takao TABEI \\ Geophysical Institute, Faculty of Science, \\ Kyoto University, Kyoto, Japan \\ (Received March 18, 1987; Revised August 24, 1987)
}

\begin{abstract}
Immediately after the 1984 Yamasaki fault earthquake of $M=5.6$, remarkable postseismic deformation, represented by an exponential function, was observed at Ikuno in the northwestern part of the Kinki district, southwest Japan. The exceptional amounts of both strain and tilt changes suggest that the local conditions of the observation site played an important role in disarranging and amplifying local strain fields. The postseismic deformation at Ikuno can be explained as an elastic deformation caused by a large pressure decrease at a disturbing source with a thrust-type pressure distribution. It can be thought of as a characteristic phenomenon occurring under the peculiar conditions in which the observations have been carried out at a closed mine that has now been fully filled up with underground water to a depth of about $1,000 \mathrm{~m}$. The disturbing source was probably caused by the diffusion of underground water, which has a high hydraulic pressure due to the high water-level in the mine. We think that the movements of underground water sometimes have an important effect on the local ground deformation in the period immediately after an earthquake.
\end{abstract}

\section{Introduction}

Continuous observations of crustal movements with high precision provide us with valuable information about ground deformation related to seismic activities. So far, in Japan great efforts have been made in detecting precursory phenomena of earthquakes for the realization of earthquake prediction. Furthermore, the spatial distribution of coseismic strain- and tilt-steps has been investigated with respect to the source mechanism in order to check the instrumental instability and the locality of the observation site or to estimate the structure and the physical properties of the crust (e.g., The Japanese Network of Crustal Movement Observatories, 1970; OKaDA, 1975).

After the coseismic steps, postseismic deformation often appears on the observation records of crustal movements, the rate of which seems to decrease exponentially with the lapse of time in most cases. SMITH and WYSS (1968) reported 
a creep motion of the San Andreas fault with a displacement of over $20 \mathrm{~cm}$ in the year after the 1966 Parkfield earthquake of $M=6.0$. This was far greater than the surface displacement at the time of the earthquake and the rate of displacement decreased with the decline of aftershock activities. YAMAUCHI (1975) has studied the relationship between earthquake magnitude and relaxation time-constant of postseismic deformation detected by continuous observations or geodetic measurements. In his study, the time constants ranged from about 20 min to about eight years and the total amount of deformation scattered widely in each case. He did not, however, rake the amount into consideration. There are many reports of investigations using an aseismic fault slip model or an asthenospheric stress relaxation model in order to clarify the mechanism of the slow and steady deformation that continues for several decades in the postseismic and interseismic stages of large earthquakes (e.g., FrTCH and Scholz, 1971; Nur and Mavko, 1974; SCHOLz and Kato, 1978; Thatcher and Rundle, 1979; Miyashita, 1983). In contrast, the variety of deformation shown by YAMAUCHI (1975) suggests that local conditions peculiar to an observation site sometimes play an important role in disarranging and amplifying the local strain fields immediately after an earthquake.

Since about 1983, seismic activity in the inner zone of southwest Japan has become considerably more active than in the previous two decades (TSUKUDA, 1986). And since 1984, some characteristic strain-changes related to the seismic activity have been observed at the Ikuno Geophysical Observation Station in the northwestern part of the Kinki district, southwest Japan. The most characteristic change was the postseismic deformation caused by the earthquake of $M=5.6$ at the Yamasaki fault on May 30, 1984 (hereafter referred to as the 1984 Yamasaki earthquake). The time variation of deformation was fittingly represented by an exponential function with a small relaxation time-constant of about five days. The total deformation was exceptionally large compared with other cases obtained so far by continuous observations, and could be attributed to the locality of the observation site.

In the present paper, we discuss a physical interpretation of the remarkable postseismic deformation with a small relaxation time-constant observed at Ikuno, and propose a possible explanation for the disturbing mechanism of the local strain fields.

\section{Postseismic Deformation of the 1984 Yamasaki Earthquake}

The Yamasaki fault system shown in Fig. 1 is one of the main strike-slip faults in southwest Japan, extending over $80 \mathrm{~km}$ in the NW-SE direction with a left-lateral slip motion of about $0.3 \mathrm{~m}$ per $10^{3}$ years (THE Research Group FOR Active FAULTS, 1980). Microearthquakes along the Yamasaki fault and in its surroundings have been continuously observed since 1964, and the characteristics of temporal variations in microearthquake activity have been studied (OIKE, 1977). An earthquake of $M=5.6$ occurred on May 30,1984 , at a depth of about $20 \mathrm{~km}$ of the 


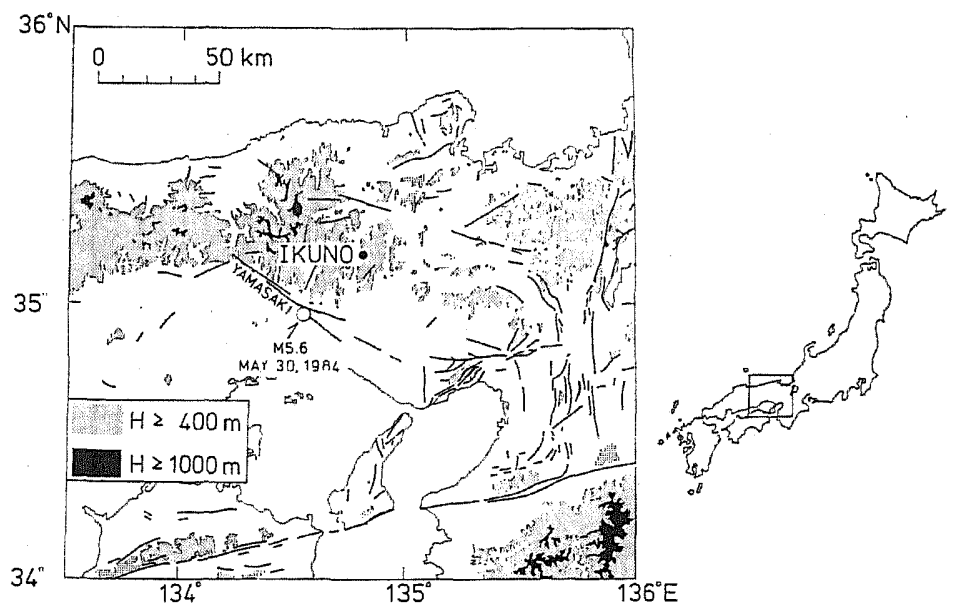

Fig. 1. Map of the northwestern part of the Kinki district, southwest Japan, showing the Yamasaki fault system and the location of Ikuno. Open circle indicates the epicenter of the earthquake of $M=5.6$ which occurred on May 30, 1984, at a depth of about $20 \mathrm{~km}$.

Yamasaki fault. This was the largest earthquake in the last 23 years in the region concerned. The focal mechanism of the main shock has been determined as a leftlateral strike-slip on the nearly vertical fault plane in the NW-SE direction. The Paxis was in an almost E-W direction (NISHIDA, 1985), which corresponds to that of the tectonic compression in this region (Huzita et al., 1973).

The Ikuno Geophysical Observation Station is about $30 \mathrm{~km}$ from the epicenter of the earthquake in a NE-direction (Fig. 1). Continuous observations of crustal movements have been carried out there since 1976. The observation tunnel is about $40 \mathrm{~m}$ below ground. Figure 2 shows the arrangements of the instruments at the station. The station is equipped with four horizontal extensometers (symbolized as EXT), four tiltmeters of the horizontal pendulum type (HPT) and water-tube tiltmeters arranged to form a quadrate (WTT) (TABEI et al., 1985). By installing the four extensometers in different azimuths, it is possible to analyze horizontal strain in several ways changing the combination of components. Similarly, several different combinations of the tiltmeters are available. We can examine the uniformity of deformation from the discrepancies between the results from the different combinations of components.

Figure 3 shows the strain records obtained by the four extensometers since October 1983, which are characterized by the remarkable contractions caused by the 1984 Yamasaki earthquake. As can be seen in the right part of Fig. 4, the postseismic strain change recorded by each instrument at Ikuno can be represented by an exponential function with a small relaxation time-constant of about five days. The deformation reached its maximum of about $3 \times 10^{-6}$ in areal strain one month 


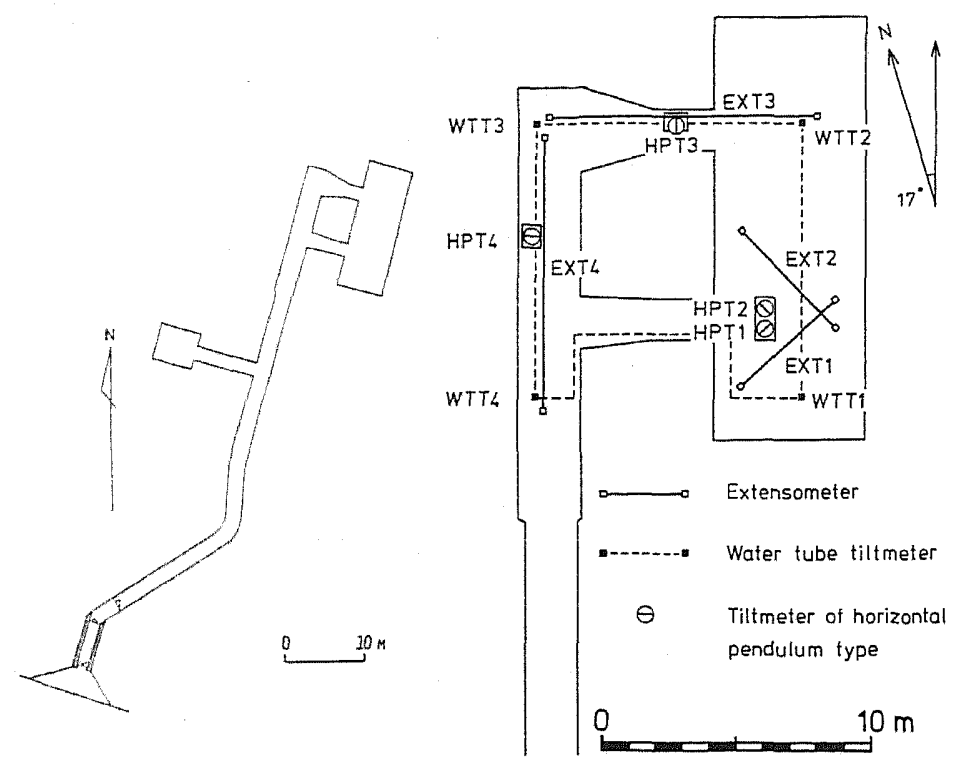

Fig. 2. Arrangements of observational instruments installed in the Ikuno Geophysical Observation Station.

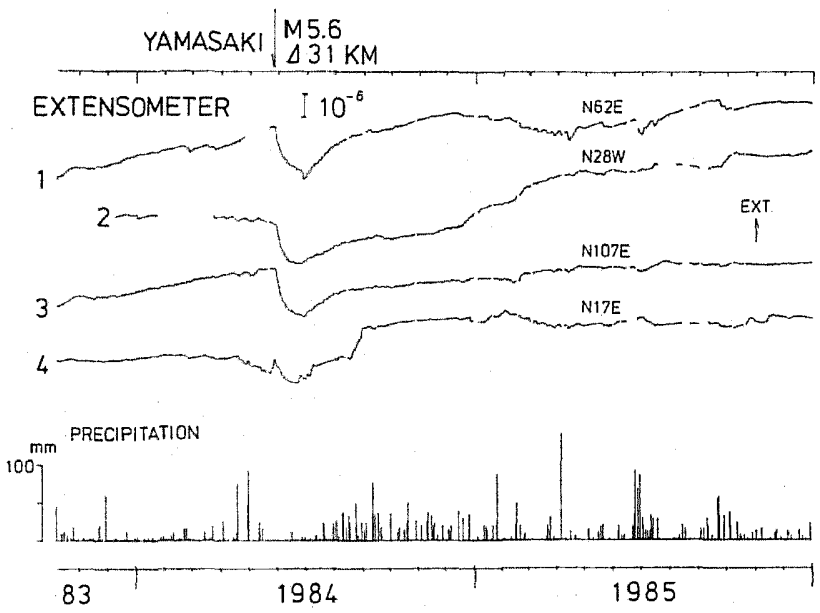

Fig. 3. Records of ground strains and daily precipitation observed at Ikuno since October 1983. Daily mean values of strains in four different azimuths are plotted.

after the main shock, and then turned to the recovery stage after being disturbed by heavy rain on June 26. Similarly, the SW-down tilt of about $3 \times 10^{-6} \mathrm{rad}$ with a time constant almost the same as that of the strain change was recorded by both 


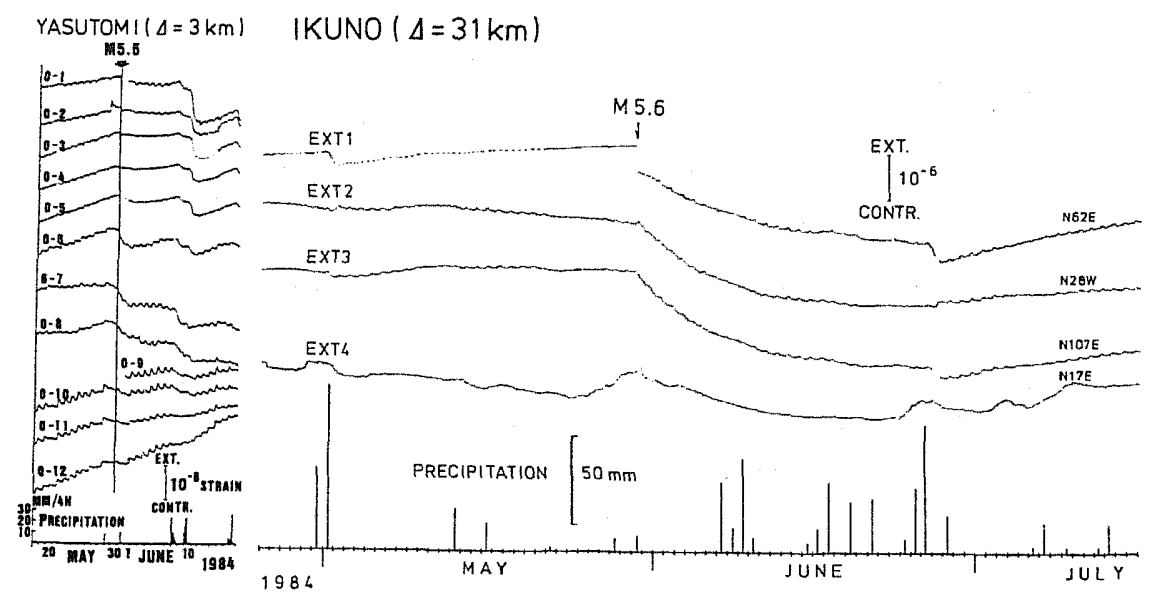

Fig. 4. Strain changes before and after the 1984 Yamasaki earthquake. (Right): Records at the Ikuno Geophysical Observation Station where the epicentral distance is about $30 \mathrm{~km}$. (Left): Records at the Yasutomi Observation Tunnel that has been excavated across the fractured zone of the Yamasaki fault and is only about $3 \mathrm{~km}$ from the epicenter (after WATANABE and OIKE, 1985). Strain components in the NW-SE direction (0-1 to 0-6), in the E-W direction (6-7), and in the NE-SW direction (0-8 to $0-12)$ are shown. Coseismic strain steps are removed from the left figure.

HPTs and WTTs (Fig. 5). Though the postseismic strain- and tilt-changes were exceedingly large, we think they were due to an elastic deformation of the uniformly strained medium for the following reasons: first, any combination of values from the four extensometers give almost the same results on the principal strains; secondly, the tilting motion was consistently recorded by two types of tiltmeters with different spans as shown in Fig. 5. For both types of tiltmeters the discrepancies between the results from the different combinations of components are very small. Nevertheless, the remarkable strain step recorded by EXT1, a contraction of about $6 \times 10^{-7}$ in an almost NE-SW direction, was not in harmony with the strain fields that we could expect from the elastic dislocation theory (SATO and MATSU'URA, 1974). Assuming that the fault is a rectangle with a length of $4 \mathrm{~km}$ and a width of $3 \mathrm{~km}$, and the amount of dislocation is $0.1 \mathrm{~m}$ of left-lateral strike-slip (NISHIGAMI and TSUKUDA, 1985), the strain step in the direction parallel to that of EXT1 is calculated to be a contraction of less than $3 \times 10^{-9}$. We attribute this discrepancy to the mechanical instability of the instrument against the sudden seismic motion. Though another type of characteristic strain-change is shown in the right part of Fig. 4, an anomalous extension recorded by only EXT4 before the earthquake, its mechanism has not yet been clarified.

During the week after the 1984 Yamasaki earthquake, exponential postseismic deformation was also observed at the Yasutomi Observation Tunnel (see the left 

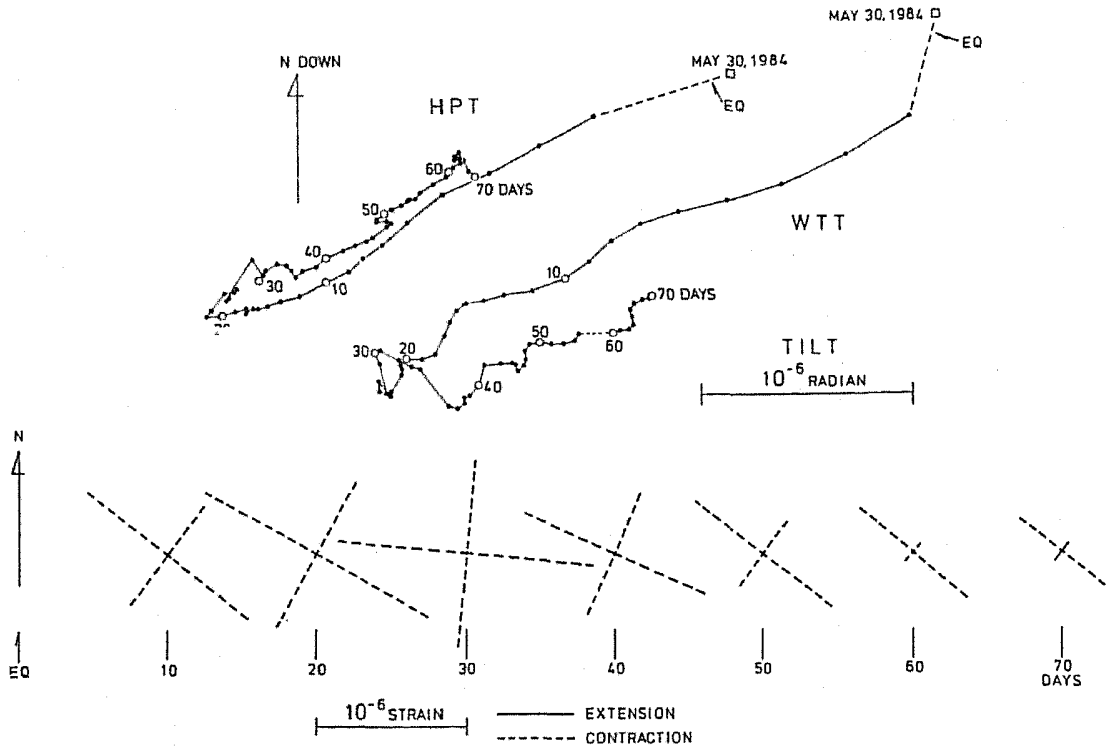

Fig. 5. Remarkable deformation observed at Ikuno after the 1984 Yamasaki earthquake. (Upper): Two vector diagrams of the maximum tilt independently recorded by the tiltmeters of the horizontal pendulum type (HPT) and the water-tube tiltmeters (WTT). (Lower): Cumulative horizontal strains after the earthquake expressed at an interval of 10 days. Both strain and tilt changes shown here are obtained by the least squares method using the observed values of all the components. The discrepancies between the results from the different combinations of components are very small.

part of Fig. 4). This tunnel was excavated across the fractured zone of the Yamasaki fault and is only about $3 \mathrm{~km}$ from the epicenter of the earthquake. WATANABE and OKKE (1985) have concluded that the observed deformation reflected the peculiar local strain effects around the observation tunnel rather than the fault displacement in the hypocentral region. This is because each component showed a different relaxation time-constant ranging from one to five days. As is shown in Fig. 4, a creep-like fault slip model in the hypocentral region does not give a consistent explanation of the amounts and time constants of the postseismic deformations observed at both Ikuno and Yasutomi, even if a creep motion actually took place.

The total strain change of over $3 \times 10^{-6}$ at Ikuno is exceedingly large compared with the other cases observed at the time of the earthquakes which occurred in inland Honshu, Japan, with magnitudes larger than that of the 1984 Yamasaki earthquake. For example, postseismic strain change produced by the 1969 Central Gifu earthquake of $M=6.6$ was smaller than $2 \times 10^{-7}$ at the Inuyama Crustal Movement Observatory, which is about $48 \mathrm{~km}$ from its epicenter (SHICHI et al., 1970). Similarly, strain change was smaller than $5 \times 10^{-7}$ at the Kamitakara Crustal 
Movement Observatory, which is about $55 \mathrm{~km}$ from the epicenter of the 1984 Western Nagano earthquake of $M=6.8$ (Dor et al., 1985). Therefore, the postseismic exponential deformation observed at Ikuno was very remarkable but can be considered not to have represented a fault displacement in the hypocenter nor regional crustal movements. As a result, we can consider that a certain mechanism disarranging and amplifying the local strain fields around the observation site was induced immediately after the earthquake.

\section{Estimation of the Disturbing Source of Local Strain Fields}

Some results on the surface displacements of semi-infinite elastic solid produced by an internal pressure source have been applied to the interpretation of ground deformation mainly accompanying large volcanic eruptions. MoGI (1958) has presented a model of the explosion type based on YAMAKAWA's results (1955) concerning the surface displacements caused by an internal spherical source with a hydrostatic pressure distribution represented by a spherical harmonics $P_{0}^{0}(\cos \theta)$. In addition, YOKOYAMA (1971) has shown the validity of an alternative model of the thrust type on the basis of SOEDA's results (1944) for a source with a pressure distribution of $P_{1}^{0}(\cos \theta)$. This model is thought to represent the approximate expression of a point force acting on the tip of intrusive rock, and has the merit that a smaller or reasonable pressure is sufficient to produce displacements the same as those in MoGr's model. Both models are applicable to the observed surface deformation, but other independent and detailed field investigations are required in order to decide the superiority of either model.

By continuous observations of strain and tilt at a fixed station, OzAwA (1981) has shown a method of estimating a disturbing source that is assumed to have a pressure distribution of the explosion type in the crust. In an attempt to interpret

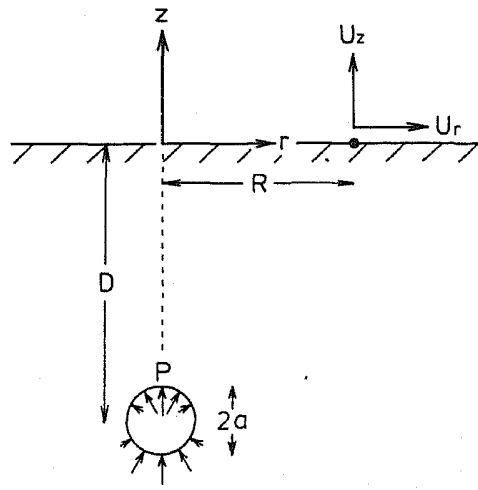

Fig. 6. Schematic illustration of an internal pressure source of the thrust type with a spherical pressure distribution of $P_{1}^{0}(\cos \theta) . P$ denotes the pressure amplitude (taken negative for the downward thrust type) and the observation site is assumed to be on the ground at the radial distance $R$. 
the postseismic deformation at Ikuno, we assume that the local strain fields around the observation site were disarranged and amplified by a certain mechanism induced by the 1984 Yamasaki earthquake, and we use OzAwA's method to estimate the disturbing mechanism. In this case, however, we prefer a thrust-type model to avoid too large a pressure at the source, though the ambiguity of the model remains.

We assume that there exists a disturbing source with a pressure distribution of $P_{1}^{0}(\cos \theta)$ at the depth $D$ in a semi-infinite medium (Fig. 6). SoEDA (1944) has shown that surface displacements at the radial distance $R$, under the condition that the Poisson's ratio is 0.25 , are expressed as

$$
\begin{aligned}
U_{r}= & \frac{a^{2} P}{6 \mu}\left\{\frac{2 D R}{\left(D^{2}+R^{2}\right)^{3 / 2}}+\frac{\left(D^{2}+R^{2}\right)^{1 / 2}-D}{R\left(D^{2}+R^{2}\right)^{1 / 2}}\right\} \\
& +\frac{a^{4} P}{126 \mu}\left\{\frac{19 D R}{\left(D^{2}+R^{2}\right)^{5 / 2}}-\frac{2 R}{D\left(D^{2}+R^{2}\right)^{3 / 2}}-\frac{2}{D^{2}} \frac{\left(D^{2}+R^{2}\right)^{1 / 2}-D}{R\left(D^{2}+R^{2}\right)^{1 / 2}}\right\}, \\
U_{\phi}= & 0, \\
U_{z}= & \frac{a^{2} P}{6 \mu}\left\{\frac{2 D^{2}}{\left(D^{2}+R^{2}\right)^{3 / 2}}+\frac{3}{\left(D^{2}+R^{2}\right)^{1 / 2}}\right\} \\
& -\frac{a^{4} P}{6 \mu}\left\{-\frac{5}{21} \frac{2 D^{2}-R^{2}}{\left(D^{2}+R^{2}\right)^{5 / 2}}+\frac{2}{7} \frac{1}{\left(D^{2}+R^{2}\right)^{3 / 2}}+\frac{2}{7 D^{2}} \frac{1}{\left(D^{2}+R^{2}\right)^{1 / 2}}\right\},
\end{aligned}
$$

where $P$ is a pressure amplitude (taken negative for the downward thrust type) and $\mu$ the rigidity of the crust. Strain and tilt at the surface are derived from Eq. (1), when $(D / a)^{2} \gg 1$, as

$$
\begin{aligned}
& \varepsilon_{r}=\frac{P}{6 \mu}\left(\frac{a}{D}\right)^{2}\left\{\frac{2\left(1-2 C^{2}\right)}{\left(1+C^{2}\right)^{5 / 2}}+\frac{1}{\left(1+C^{2}\right)^{3 / 2}}-\frac{\left(1+C^{2}\right)^{1 / 2}-1}{C^{2}\left(1+C^{2}\right)^{1 / 2}}\right\}, \\
& \varepsilon_{\phi}=\frac{P}{6 \mu}\left(\frac{a}{D}\right)^{2}\left\{\frac{2}{\left(1+C^{2}\right)^{3 / 2}}+\frac{\left(1+C^{2}\right)^{1 / 2}-1}{C^{2}\left(1+C^{2}\right)^{1 / 2}}\right\} \\
& T=-\frac{P}{6 \mu}\left(\frac{a}{D}\right)^{2}\left\{\frac{6 C}{\left(1+C^{2}\right)^{5 / 2}}+\frac{3 C}{\left(1+C^{2}\right)^{3 / 2}}\right\} \\
& C=\frac{R}{D}
\end{aligned}
$$

where $\varepsilon_{r}$ and $\varepsilon_{\phi}$ are the radial and the tangential components of strain, respectively, and $T$ is the tilt in radial direction measured in units of radian (taken negative when the origin uplifts). The sign of $\varepsilon_{\phi}$, which is always opposite to that of $T$, indicates whether the source is an upward or a downward thrust. Thus, estimations of the position and type of the source are possible according to the relationship between the signs of $\varepsilon_{\phi}$ and $T$. Moreover, the variables $\left[\varepsilon_{r}\right],\left[\varepsilon_{\phi}\right]$, and $[T]$ are defined as follows; 


$$
\begin{aligned}
& {\left[\varepsilon_{r}\right]=\frac{1}{\varepsilon_{r_{0}}}\left\{\frac{2\left(1-2 C^{2}\right)}{\left(1+C^{2}\right)^{5 / 2}}+\frac{1}{\left(1+C^{2}\right)^{3 / 2}}-\frac{\left(1+C^{2}\right)^{1 / 2}-1}{C^{2}\left(1+C^{2}\right)^{1 / 2}}\right\},} \\
& {\left[\varepsilon_{\phi}\right]=\frac{1}{\varepsilon_{\phi_{0}}}\left\{\frac{2}{\left(1+C^{2}\right)^{3 / 2}}+\frac{\left(1+C^{2}\right)^{1 / 2}-1}{C^{2}\left(1+C^{2}\right)^{1 / 2}}\right\},} \\
& {[T]=-\frac{1}{T_{0}}\left\{\frac{6 C}{\left(1+C^{2}\right)^{5 / 2}}+\frac{3 C}{\left(1+C^{2}\right)^{3 / 2}}\right\}}
\end{aligned}
$$

where $\varepsilon_{r_{0}}$ and $\varepsilon_{\phi_{0}}$ are the observed strains and $T_{0}$ the observed tilt. When the assumed pressure source is real and $\varepsilon_{r_{0}}, \varepsilon_{\phi_{0}}$, and $T_{0}$ are perfectly equal to the values calculated from Eq. (2), the three curves of $\left[\varepsilon_{r}\right],\left[\varepsilon_{\phi}\right]$, and $[T]$ plotted against $C$ intersect each other at a point for the specific value of $C$ (OZAWA, 1981), and then,

$$
\left[\varepsilon_{r}\right]=\left[\varepsilon_{\phi}\right]=[T]=\frac{6 \mu}{P}\left(\frac{D}{a}\right)^{2} .
$$

As is evident from Fig. 5, the direction of the maximum tilt of the postseismic deformation does not always coincide with one of the principal strain axes. Such a small discrepancy in direction may be caused by the factors ignored here such as a topographic effect, but we do not know its mechanism. Nevertheless, it is clear that $\varepsilon_{\phi}$ is always negative (contraction) in this case and $T$ is consequently positive. This relationship between the signs of $\varepsilon_{\phi}$ and $T$ implies that there exists a pressure source of the downward thrust type far in the SW-direction from the observation site.

For example, the strain and tilt that occurred during the 10 days after the main shock of the 1984 Yamasaki earthquake are approximately estimated as follows:

$$
\begin{array}{ll}
\varepsilon_{r_{0}}=-0.67 \times 10^{-6} & (\mathrm{NE}-\mathrm{SW}), \\
\varepsilon_{\phi_{0}}=-1.42 \times 10^{-6} & (\mathrm{NW}-\mathrm{SE}), \\
T_{0}=2.34 \times 10^{-6} & (\mathrm{SW}-\text { down }),
\end{array}
$$

where any small discrepancy in direction is neglected. The three curves of $\left[\varepsilon_{r}\right],\left[\varepsilon_{\phi}\right]$, and $[T]$ are plotted against $C$ in the left part of Fig. 7. They form a very small triangle around $C=0.53$, and then give a value of $-1.24 \times 10^{6}$ for $6 \mu(D / a)^{2} / P$ in Eq. (4). Similarly, from the total amount of postseismic deformation, we can determine that the value of $C$ is 0.54 and that of $6 \mu(D / a)^{2} / P$ is $-0.97 \times 10^{6}$ (see the right part of Fig. 7). Judging from the adjacent intersections of the three curves in Fig. 7, a pressure source model of the downward thrust-type is applicable to the interpretation of the postseismic strain- and tilt-changes observed at Ikuno.

Equations (1) and (2) are derived originally under the assumption of $(D / a)^{2} \gg 1$ (SOEDA, 1944). For the case of rock intrusion, for example, $a$ is probably very small compared with $D$ while $P$ may be rather large. As is discussed in the next section, however, we suppose a pressure decrease due to diffusion of underground water as a disturbing mechanism in this case, and therefore, we are convinced that $a$ does not 


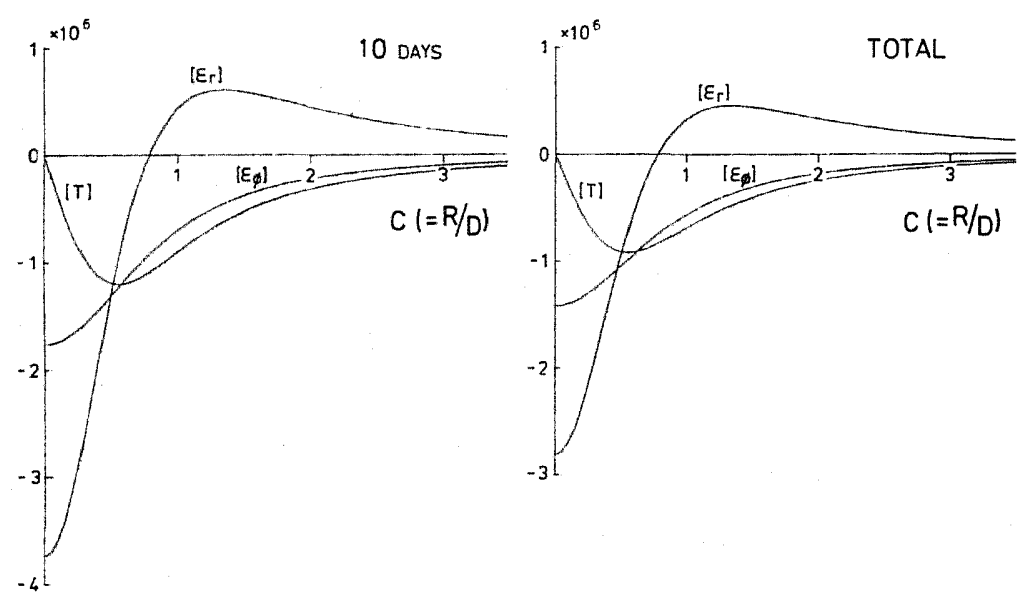

Fig. 7. Variations of $\left[\varepsilon_{r}\right],\left[\varepsilon_{\phi}\right]$, and $[T]$ as functions of $C$ based on the observational results on the postseismic deformation of the 1984 Yamasaki earthquake. The definitions of $\left[\varepsilon_{r}\right],\left[\varepsilon_{\phi}\right]$, and $[T]$ are given in Eq. (3) in the text. An intersection of the three curves gives a value of $6 \mu(D / a)^{2} / P$, and $C$ value which is a ratio of the horizontal distance to the depth of the pressure source.

take so small a value compared with $D$. Here we assume $D / a=10$, which is considered to be moderate and sufficiently realistic (YoKOYAMA, 1971). However, it should be noticed that this assumption and consequently the estimated pressure change contain large uricertainties. If the value of $D / a$ becomes much smaller or the shape of the source is widely different from a sphere, a simple application of Eqs. (1) and (2) is no longer possible and other treatments such as a multiple model as a superposition of simple models (HaGiwara, 1977) may be required. Assuming that $\mu$ of the uppermost part of the crust is $10^{11} \mathrm{dyn} \cdot \mathrm{cm}^{-2}$, the approximate pressure decrease at the source during the 10 days after the earthquake is estimated to be 48 bar. Similarly, the total decrease in pressure expected from the total amount of the postseismic deformation is 62 bar. The mechanism of the pressure decrease of the order of several tens of bar is discussed in the next section.

We also estimated a disturbing source of the explosion type using a method similar to that employed here. However, the three curves of $\left[\varepsilon_{r}\right],\left[\varepsilon_{\phi}\right]$, and $[T]$ did not converge on a point and the approximately estimated pressure decrease at the source was larger than 300 bar, which was too large for the event that occurred in the uppermost part of the crust. Thus, we could not accept an explosion-type model as a disturbing mechanism of the local strain fields in this case.

\section{Discussion}

The observations have been carried out in the former underground powder storage of the closed Ikuno mine. Operations at the mine were stopped at the 
beginning of 1973, and thereafter a large amount of water began to be injected into the deep mine. At that time, the lowest level in the mine had reached a depth of about $1,000 \mathrm{~m}$ below ground. Just after the water injection started, small ground tremors occurred in succession, which is interpreted as being caused by a disturbance of the unstable equilibrium between tectonic stress and stress concentration around the excavated galleries due to the water injection (TANAKA and NisHIDA, 1977). In 1976 the water level was more than $800 \mathrm{~m}$ from the bottom of the mine, and since then, a series of microearthquakes were induced (Fig. 8) with the increase of pore pressure in the pre-existing faults due to the rise in the water level (TANAKA and OKA, 1979). From the epicentral distribution of water-induced microearthquakes shown in Fig. 9, it can be considered that underground water with a high hydraulic pressure due to the high water-level in the mine slowly permeated the fault systems and veins in the Ikuno area from the excavated galleries in the closed mine. Since 1978 the activity of induced earthquakes has declined because stress state in the Ikuno area probably came up to a new equilibrium. The water injected after 1973 is estimated as several ten millions of tons, and all the galleries underlying the observation tunnel have now been filled up with water. It is strongly suggested, therefore, that the movements of underground water produced by the earthquake have an important effect in disarranging and amplifying the local strain fields.

If seismic motions induce microfractures in a certain location underground that includes pre-existing planes of weakness near a water-retaining layer, some of the underground water, which is under a high hydraulic pressure, will permeate the new fissures and diffuse through them. Consequently, there will be a rapid pressure decrease. This can probably be represented by an exponential function and becomes a disturbing source that disarranges and amplifies the local strain fields. On the

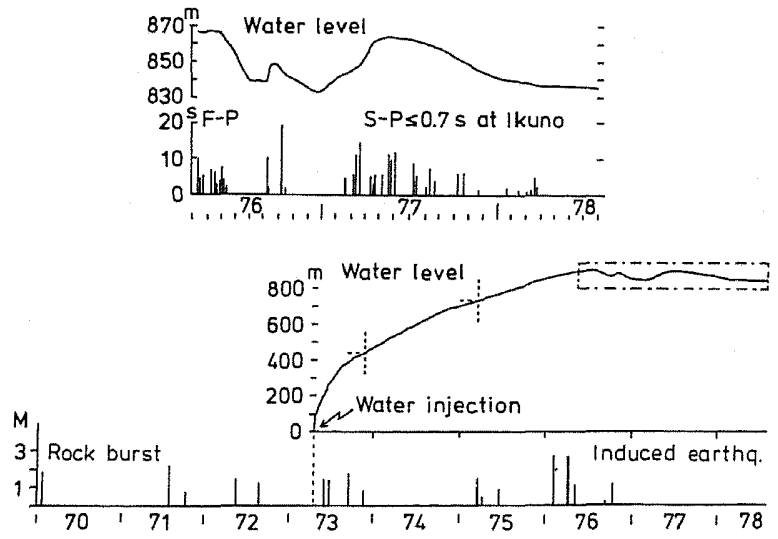

Fig. 8. Relationship between water level in the closed Ikuno mine and occurrences of water-induced microearthquakes in the surroundings (after TANAKA and OKA, 1979). Clear correlation between them is shown in the upper figure. The location of the mine and the epicentral distribution of the microearthquakes are shown in Fig. 9. 


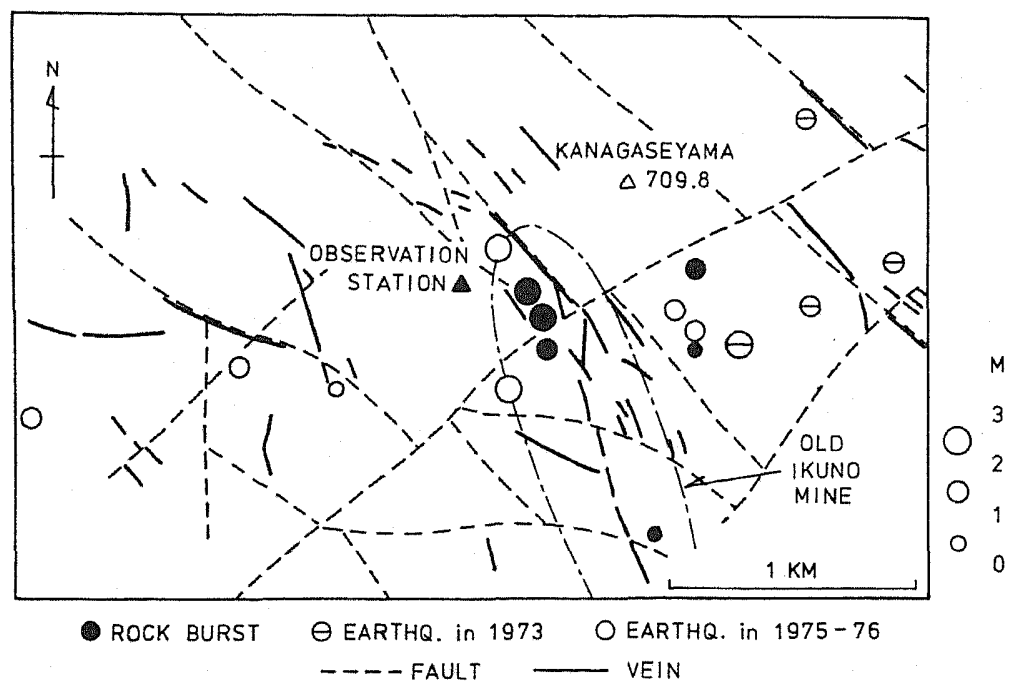

Fig. 9. The epicentral distribution of rock bursts and water-induced microearthquakes (after TANAKA and NiSHIDA, 1977) as well as the fault systems and veins in Ikuno area.

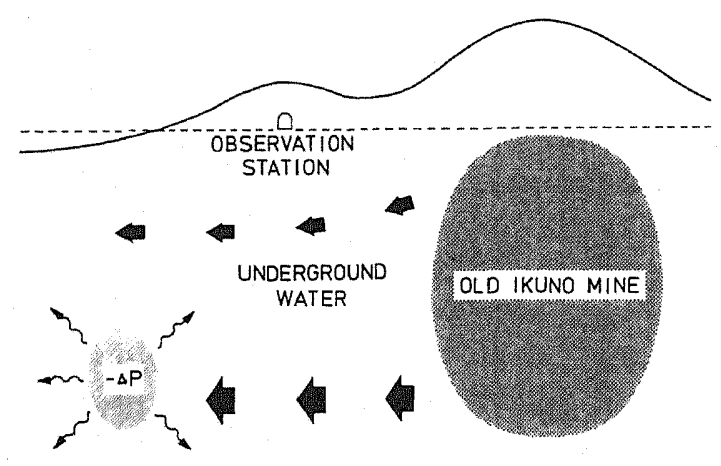

Fig. 10 Schematic illustration of the disturbing mechanism of local strain fields. $-\triangle P$ denotes a rapid pressure decrease caused by the diffusion of underground water. Underground water with a high hydraulic pressure, on the other hand, continues to permeate slowly from the old mine functioning as a huge water reservoir with a depth of about $1,000 \mathrm{~m}$.

other hand, underground water with a high hydraulic pressure continues to permeate slowly from the excavated galleries, which function as a huge water reservoir with a depth of about $1,000 \mathrm{~m}$. The recovery stage of strain fields observed is construed as being due to a slow resupply of permeated underground water into the disturbing source. As a result, the remarkable postseismic deformation at Ikuno 
after the 1984 Yamasaki earthquake can be thought of as a characteristic phenomenon occurring under the peculiar conditions in which the observations have been carried out at a closed mine that has now been fully filled up with water and functions as a huge water reservoir with a depth of about $1,000 \mathrm{~m}$. Thus, it is interpreted as a transient elastic deformation caused by a pressure decrease of the order of several tens of bar due to the diffusion of underground water produced by the earthquake. This disturbing mechanism of strain fields is illustrated in Fig. 10.

In reality, the disturbing mechanism of the local strain fields is probably more complicated, and the relaxation time-constant of deformation is still not quantitatively clarified. And there may exist other factors ignored here such as a topographic effect. However, we are convinced that the movements of underground water produced by the earthquake sometimes have an important effect on the postseismic deformation of the ground surface immediately after an earthquake.

\section{Conclusions}

Immediately after the 1984 Yamasaki earthquake, remarkable postseismic deformation was observed at Ikuno, which is about $30 \mathrm{~km}$ from the epicenter. The time variation of the deformation was fittingly represented by an exponential function with a small relaxation time constant of about five days. The total amount of deformation reached $3 \times 10^{-6}$ of contraction in areal strain and $3 \times 10^{-6} \mathrm{rad}$ in maximum tilt, which were exceptionally large values compared with other cases obtained by continuous observations at the time of the earthquakes with magnitudes larger than that of the 1984 Yamasaki earthquake. It is strongly suggested that the local conditions of the observation site played an important role in disarranging and amplifying local strain fields.

Based on the observational results, we estimated a disturbing mechanism of local strain fields induced by the earthquake. Although there is an ambiguity of the model, the postseismic deformation observed is successfully interpretable as an elastic deformation caused by a large pressure decrease at the underground pressure source with a thrust-type pressure distribution. The pressure decrease at the source is probably caused by the diffusion of underground water which has filled the fault systems and veins in the Ikuno area with a high hydraulic pressure due to the high water-level in the closed mine.

We still have not clarified the relaxation time-constant of the deformation quantitatively, and further field investigations are required to understand the mechanism in more detail. However, we are convinced that the movements of underground water sometimes have an important effect on the local surface deformation immediately after an earthquake.

The author expresses his sincere thanks to Mr. Yutaka Tanaka and Prof. Ichiro Nakagawa of Kyoto University for their helpful advice throughout the course of this study and for critical reading of the manuscript. He also acknowledges the members of Geophysical 
Institute, Faculty of Science, Kyoto University, for their helpful discussions.

\section{REFERENCES}

DoI, H., Y. WADA, M. KATO, H. WADA, and Y. Hoso, Ground deformation observed at Kamitakara (Up to Dec. 1984), Disas. Prev. Res. Inst. Ann., Kyoto Univ., 28B-1, 79-90, 1985 (in Japanese).

FrTCH, T. J. and C. H. SHolz, Mechanism of underthrusting in southwest Japan: A model of convergent plate interactions, J. Geophys. Res., 76, 7260-7292, 1971.

Hagrwara, Y., Matsushiro uplift as a multiple Mogi model, J. Geod. Soc. Jpn., 23, 25-35, 1977 (in Japanese).

Huzita, K., Y. Kishimoto, and K. Shiono, Neotectonics and seismicity in the Kinki area, Southwest Japan, J. Geosci. Osaka City Univ., 16, 93-124, 1973.

MiYASHITA, K., Surface displacement patterns associated with asthenospheric stress relaxation following major underthrust earthquakes, Zisin (J. Seismol. Soc. Jpn.), 36, 541-550, 1983 (in Japanese).

MOGI, K., Relations between the eruptions of various volcanoes and the deformations of the ground surfaces around them, Bull. Earthq. Res. Inst., Univ. Tokyo, 36, 99-134, 1958.

NisHIDA, R., Focal mechanism-Symposium on the Yamasaki fault, The Earth Monthly, 67, 49-53, 1985 (in Japanese).

Nishigami, K. and T. TsuKudA, Occurrence process of the earthquake-Symposium on the Yamasaki fault, The Earth Monthly, 67, 43-48, 1985 (in Japanese).

Nur, A. and G. Mavko, Postseismic viscoelastic rebound, Science, 183, 204-206, 1974.

OIKE, K., Seismic activities and crustal movements at the Yamasaki fault and surrounding regions in the Southwest Japan, J. Phys. Earth, 25, Suppl., S31-S41, 1977.

OKADA, Y., Strain- and tilt-steps associated with the two earthquakes which occurred in the east off Hachijojima, Japan, on February 29 and December 4, 1972, Zisin (J. Seismol. Soc. $J p n$.), 28, 387-413, 1975 (in Japanese).

OzAWA, I., Estimation of the disturbing source in the crust by means of observations of the crustal tilt and strain, J. Geod. Soc. Jpn., 27, 297-300, 1981.

SATO, R. and M. MATSU'URA, Strains and tilts on the surface of a semi-infinite medium, $J$. Phys. Earth, 22, 213-221, 1974.

Scholz, C. H. and T. KATO, The behavior of a convergent plate boundary: Crustal deformation in the south Kanto district, Japan, J. Geophys. Res., 83, 783-797, 1978.

SHICHI, R., K. IDA, and T. YAMAUCHI, Some considerations on the strain-step associated with the earthquake of the central part of Gifu prefecture, September 9, 1969, Bull. Earthq. Res. Inst., Univ. Tokyo, 48, 1241-1249, 1970 (in Japanese).

SMITH, S. W. and M. Wyss, Displacement on the San Andreas fault subsequent to the 1966 Parkfield earthquake, Bull. Seismol. Soc. Am., 58, 1955-1973, 1968.

SOEDA, K., On the deformations produced in a semi-infinite elastic solid by an interior source of stress, Q. J. Seismol., Jpn. Meteoral. Agency, 13, 263-291, 1944 (in Japanese).

TABEI, T., K. Fujimori, and Y. TANAKA, Observations of crustal movements at Ikuno (1977-1983), J. Geod. Soc. Jpn., 31, 189-201, 1985 (in Japanese).

TANAKA, Y. and R. NisHIDA, Generation mechanism of rock bursts and microearthquakes induced by water-injection into a deep abandoned mine, Proc. 5th Jpn. Symp. Rock Mech., 91-96, 1977 (in Japanese). 
TANAKA, Y. and Y. OKA, Generation mechanism of rock bursts and water-induced earthquakes under the tectonic stress field, Rock Mech. Jpn., 3, 71-73, 1979.

ThATCher, W. and J. B. Rundle, A model for the earthquake cycle in underthrust zones, $J$. Geophys. Res., 84, 5540-5556, 1979.

The Japanese Network of Crustal Movement Observatories, Spatial distribution of strain-steps associated with the earthquake of the central part of Gifu prefecture, September 9, 1969, Bull. Earthq. Res. Inst., Univ. Tokyo, 48, 1217-1233, 1970 (in Japanese).

The Research Group for Active Faults, Active Faults in Japan, the University of Tokyo Press, Tokyo, 239 pp., 1980 (in Japanese).

Tsukuda, T., Is the present seismicity active?, Rep. Meet. Stud. Earthq. Predict., Kyoto Univ., 9, 3-10, 1986 (in Japanese).

WATANABE, $K$. and.K. OIKE, Crustal deformations related to the Yamasaki fault earthquake on May 30th, 1984, M 5.6, observed at the Yasutomi Observation. Tunnel, Disas. Prev. Res. Inst., Ann., Kyoto Univ., 28B-1, 99-109, 1985 (in Japanese).

YAMAKAWA, N., On the strain produced in a semi-infinite elastic solid by an interior source of stress, Zisin (J. Seismol. Soc. Jpn.), 8, 84-98, 1955 (in Japanese).

YamauchI, T., On the elastic after-effect associated with earthquake, J. Geod. Soc. Jpn., 21, 75-80, 1975 (in Japanese).

Yokoyama, I., A model for the crustal deformations around volcanoes, J. Phys. Earth, 19, 199-207, 1971. 